\title{
Isolation and selection of fluorescent pseudomonads based on multiple plant growth promotion traits and siderotyping
}

\author{
Jayamohan Subramanian $^{1}$, and Kumudini Satyan ${ }^{1 *}$
}

\begin{abstract}
Fluorescent pseudomonads, acclaimed plant associated bacterial group, are well-known plant growth promoting-biocontrol agents in rhizosphere arena. In this study, 144 fluorescent pseudomonad isolates from rhizosphere soil samples were screened with King's medium B supplemented with 8-hydroxyquinoline (8-HQ) chelator and comprehensively profiled for plant growth promotion viz., production of indole acetic acid (IAA), siderophore, ammonia, hydrogen cyanide, motility, phosphate solubilization, root growth promotion, and biofilm forming ability, along with two known control strains of pseudomonads. Iron and IAA regulated secondary metabolite siderophore production were investigated quantitatively. All isolates were positive for ammonia production and motility; $46 \%$ isolates were positive for hydrogen cyanide, $44 \%$ shown positivity for phosphate solubilization, and $40 \%$ isolates for siderophore production. Siderotyping showed production of hydroxamate type of siderophores which are known to be more efficient biocontrol agents. All isolates stimulated root growth to varying extent and had potentiality to form biofilms, a critical constituent for survival on different environments. Forty-two isolates of pseudomonads showed antagonistic behavior against the deleterious fungal pathogen Fusarium oxysporum (MTCC1755). Based on the above observations and statistical analysis, 11 isolates were shortlisted for further scrutiny. The study of biogeographic correlation and secondary metabolite profiling in association with plant growth promotion focalizes significant assessment on the behavior and antagonistic action, which probably brings out a competent biocontrol agent in a sustainable eco-friendly dimension.
\end{abstract}

Key words: IAA, PGPR, plant growth promotion, rhizosphere, siderophore.

\section{INTRODUCTION}

Rhizosphere is rich in microbial diversity and harbors a variety of micro flora that influences plant growth and development. One of the other most important effective factors in increasing plant yield is seed priming with plant growth promoting rhizobacteria, referred to as PGPR (Saharan and Nehra, 2011), which are a group of bacteria that competitively colonize plant roots and stimulate plant growth and yield (Bhattacharyya and Jha, 2012), and/or reduce plant disease incidence. The PGPR concept has been vindicated by the isolation of many bacterial strains that fulfill at least two of the three criteria - aggressive colonization, plant growth stimulation, and biocontrol (Beneduzi et al., 2012). The mechanisms that are involved in this process can include mineral solubilization, release of phytohormones viz., indole acetic acid (IAA), cytokinin, and volatile growth stimulants viz., ethylene

\footnotetext{
'Jain University, Department of Biotechnology, Jayanagar, Bangalore 560011, India.

*Corresponding author (kumudini_satyan@yahoo.co.in).

Received: 25 October 2013.

Accepted: 30 May 2014.
}

doi: $10.4067 /$ S0718-58392014000300010 and 2,3-butanediol (Haas and Défago, 2005). Different genera of PGPR, including Azotobacter, Azospirillum, Pseudomonas, Acetobacter, Burkholderia, Bacillus, Paenibacillus, Pseudomonas spp., are often used as model root-colonizing bacteria (Saharan and Nehra, 2011).

Fluorescent pseudomonads are a group of PGPR that produce fluorescent colonies and form a considerable part of the rhizospheric microbial community which influence plant growth in a multitude manner (Selvakumar et al., 2011). They form a major group within the rRNA homology group I of Pseudomonas 'sensu lato' and are characterized by abundant production of fluorescent pyoverdin pigments in medium containing low $\mathrm{Fe}$ (Palleroni, 1984). Some molecules present in the root exudates can serve as chemo-attractants for the introduced strains (Neal et al., 2012). Production of IAA is one of the mechanism through which the PGPR magnifies growth and development. Bacterial IAA increases root surface area and length and thereby provides the plant greater access to soil nutrients (Glick, 2012). The aim of the study was to analyze complex interaction of plant-bacteria in the light of the pseudomonads exerted plant growth promoting characteristics and antagonistic action against soil fungus that presumably lead to the development of induced resistance in plants. 


\section{MATERIALS AND METHODS}

Site description, soil sampling, isolation, and characterization of fluorescent pseudomonads

Rhizosphere soil samples of eight different disease free plants from different locations in India were collected: Capsicum annuum L. (Mysore, Karnataka); rice (Oryza sativa L.; I-Patna, Bihar); cardamom (Elettaria cardamomum [L.] Maton), Curcuma longa L., Oryza sativa L. (II-Idukki, Kerala); Nyctanthes arbor-tristis L. (Gangtok, Sikkim); tomato (Solanum lycopersicum L.), and corn (Zea mays L.; Bangalore, Karnataka). Plants were carefully covered in plastic bags and gently transferred to the laboratory. Serial dilution of soil adhering to roots was carried out according to Alexander (1965). Colonies were isolated as indicated by Fallahzadeh-Mamaghani et al. (2009) in King's B (KB) medium supplemented with 8-hydroxyquinoline (8-HQ). Two strains of Pseudomonas fluorescens obtained from National Bureau of Agriculturally Important Insects (NBAII-Indian Council of Agricultural Research), Bangalore (PC1), and RomVijay Biotech, Puducherry (PC2), were used as controls.

Phenotypic level characterization of pseudomonads were carried out by subjecting the bacterial isolate to morphological (Gram's nature) and biochemical characterization (hydrolysis of starch, gelatine, urea, casein, glucose fermentation, production of $\mathrm{H}_{2} \mathrm{~S}$, catalase, and oxidase) (Cappuccino and Sherman, 1992). Bacterial inoculum with a concentration of $1 \times 10^{8} \mathrm{CFU} \mathrm{mL}^{-1}$ was used throughout study.

\section{Plant growth promotion (PGP) traits}

Synthesis of ammonia by microorganisms was studied using $24 \mathrm{~h}$ old cultures. Isolates were inoculated in $10 \mathrm{~mL}$ peptone water $(1 \% \mathrm{w} / \mathrm{v})$ and incubated at $37 \pm 2{ }^{\circ} \mathrm{C}$ for 48 $72 \mathrm{~h} ; 0.5 \mathrm{~mL}$ Nessler's reagent (Nice, India) were added and observed for brown yellow color (Cappuccino and Sherman, 1992). Production of hydrogen cyanide (HCN) was tested in all isolates according to Lorck (1948). To find out the motility, isolates were stab inoculated on to indole ornithine medium containing $0.4 \%$ agar (Murinda et al., 2002) and growth was visually encoded as positive (+) and negative (-). To evaluate the capability to solubilize phosphate, isolates were streaked on the surface of Pikovskaya agar and phosphate solubilizing activity was estimated after $7 \mathrm{~d}$ of incubation at $36 \pm 2{ }^{\circ} \mathrm{C}$ (Sharma et al., 2011). Production of auxin by pseudomonads was studied with all isolates. Qualitative analysis of IAA was carried out according to Bric et al. (1991) and quantitative analysis was carried out according to Pedraza et al. (2004). All isolates were tested for their ability to form solid surface associated biofilm with minor modification from Yamaga et al. (2010).

Effect of the pseudomonad isolates on induction of growth promotion was demonstrated in tomato.
Disinfected tomato seeds ('PKM-1', 'LOT-208') were used for study. The bacterial isolates were grown in KB broth at $37 \pm 2{ }^{\circ} \mathrm{C}$ for $48 \mathrm{~h}$ under shaking condition, and centrifuged $\left(6000 \mathrm{rpm}, 15 \mathrm{~min}, 4^{\circ} \mathrm{C}\right)$. Bacterial cells were harvested and resuspended in $0.01 \mathrm{M}$ phosphate buffer $(\mathrm{pH}$ 7.0). Bacterial cell concentration was adjusted to $\sim 1 \times 10^{8}$ $\mathrm{CFU} \mathrm{mL} \mathrm{L}^{-1}\left(\mathrm{OD}_{660}=0.3\right)$. Germination test was carried out according to ISTA (1993). Distilled water treated seeds served as control. Root length (RL) and shoot length (SL) were measured, vigor index (VI) and germination \% ware calculated (Baki and Anderson, 1973). Vigor index (VI) was calculated as: percentage of germination $\times$ seedling length.

Siderophore assay was carried out qualitatively and quantitatively. Qualitative analysis was carried out using chrome azurol S (CAS) agar (HiMedia, Mumbai, India) as per Alexander and Zuberer (1991) and estimation of siderophore was carried out by CAS-shuttle assay (Ali and Vidhale, 2011), using the molar extinction coefficient of $100000 \mathrm{M}^{-1} \mathrm{~cm}^{-1}$ (at $630 \mathrm{~nm}$ ) (Schwyn and Neilands, 1987). In order to expose the chemical nature of siderophore, a thin layer chromatography (TLC Silica gel $60 \mathrm{~F}_{254}$, Merck, Germany) was carried out (Bhattacharya, 2010). Siderophore typing for hydroxamates was performed according to Neilands (1981) and confirmed by the tetrazolium test (Snow, 1954). Catecholates and carboxylates were analyzed as Neilands (1981) and Shenker et al. (1992), respectively.

Fungal inhibition capacity of the isolates was carried out using the well diffusion assay against Fusarium oxysporum (MTCC1755) using spore suspension of $2 \times$ $10^{6}$ spores $\mathrm{mL}^{-1}$ in $0.85 \%(\mathrm{w} / \mathrm{v})$ sterile saline (Zongzheng et al., 2009).

In order to shortlist the best functional pseudomonad, a ranking system based on PGP potential was applied. The results were compared by non-parametric Kendall's concordance coefficient analysis (García-Gutiérrez et al., 2012) using SPSS 18. Graphs and two-way ANOVA analyses were prepared using Graph Pad Prism 6.01. The shortlisted isolates were analyzed through Mean centered principal component analysis (using CAMO Unscrambler 10.3 trial version) on the summarized data table in order to search the possible variance based on growth promotion traits and antagonistic action with respect to control strains.

\section{RESULTS AND DISCUSSION}

From eight different rhizosphere soil samples, 144 isolates of fluorescent pseudomonads were obtained, three from C. annum, three from E. cardamomum, 45 from C. longa, 30 from $O$. sativa-I, 28 from $N$. arbor-tristis, two from $O$. sativa-II, 18 from tomato, and 15 from corn. Maximum number of fluorescent colonies was observed at $0 \mathrm{mg} \mathrm{L}^{-1}$ 8-HQ concentration, but was visibly mixed with nonfluorescent colonies and undifferentiated in culture plates. It was observed that the colony number reduced gradually 
with increase in 8-HQ concentration (Figure 1). At 120 $\mathrm{mg} \mathrm{L}^{-1} 8$-HQ concentration, bacterial colonies showed ideal characteristics of fluorescent pseudomonads with high intensity of fluorescence.

Isolates were biochemically characterized for their ability to produce amylase, gelatinase, urease, caseinase, catalase, oxidase, and ability to reduce glucose and sulfates. Results of biochemical characterization indicated that isolates belong to genus Pseudomonas. The biochemical characterization results of shortlisted fluorescent pseudomonads isolates are given in Table 1. Biochemical test results showed a vast diversity in the microbial flora among the isolated fluorescent pseudomonads from rhizospheric soil. Further the isolates were also evaluated for the different traits typically associated with the PGP such as production of ammonia, hydrogen cyanide, motility, phosphate solubilization, production of phytohormones, siderophore, promotion of root augmentation and germination.

All the isolates including controls were positive for ammonia synthesis (Figure 2), which is an important trait of PGPR that may indirectly influence plant growth (Karuppiah and Rajaram, 2011; Raval and Desai, 2012; Kayasth et al.,2013). Sixty seven isolates showed hydrogen cyanide production as indicated by the discoloration of

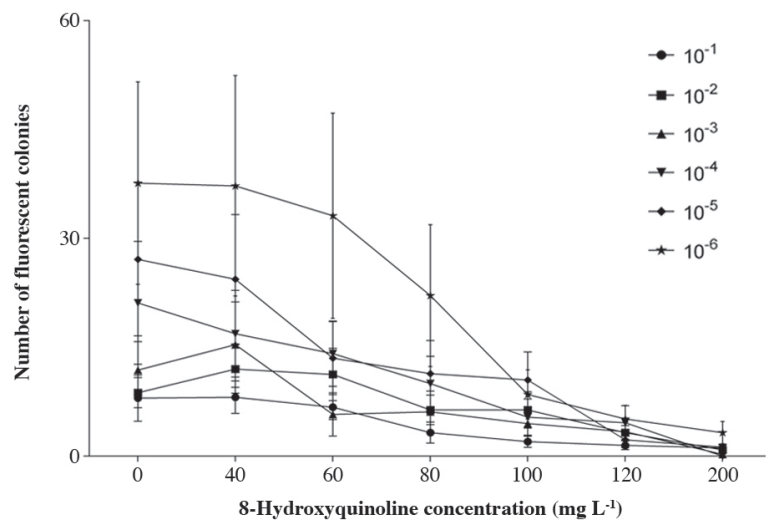

Data represented are mean of eight samples. Error bars indicate standard error. Two way ANOVA showed a significant $\mathrm{p}$ value (0.0049).

Figure 1. Number of colonies on King's B medium with increasing concentration of 8-hydroxyquinoline (8-HQ).

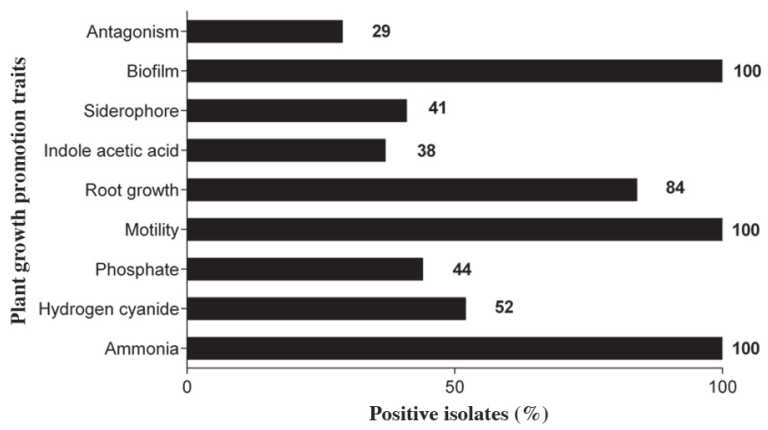

Figure 2. Percentage of isolates positive for plant growth promotion attributes.

the filter paper from orange to brown after incubation. Although cyanide acts as a general metabolic inhibitor, host plants are not harmfully affected by rhizobacterial production of hydrogen cyanide and host specific rhizobacteria can operate as biological control agents (Saharan and Nehra, 2011). In the present study, isolates with antagonistic activity did not show any relation with hydrogen cyanide or siderophore production. Hence, it can be speculated that production of bacterial antibiotics subsequently leads to fungal inhibition. Soil bacteria particularly, fluorescent pseudomonads have a tendency to produce an array of low-molecular-weight metabolites, some of which are potent antifungal agents. Volatile compounds such as hydrogen cyanide and ammonia are also implicated as important metabolites in biocontrol action (Raval and Desai, 2012; Zhuang et al., 2013).

All the tested isolates displayed moderate to high motility under laboratory conditions. de Weert et al. (2002) established that motility in Pseudomonas is a major trait for root colonization, and the organic acids such as malic acid and citric acid are among major chemo-attractants for $P$. fluorescens in the tomato rhizosphere. This study is supported by Choi et al. (2006) that biofilm formation and swarming motility may contribute to bacterial colonization and stable maintenance of antifungal compounds on plant surface.

There is significant amount of insoluble $\mathrm{P}$ that is unavailable for plant growth. Phosphate solubilization and mineralization is carried out through different mechanisms

Table 1. Biochemical properties of shortlisted fluorescent pseudomonads isolates.

\begin{tabular}{|c|c|c|c|c|c|c|c|c|}
\hline Isolates & Amylase & $\mathrm{H}_{2} \mathrm{~S}$ & Gelatinase & Urease & Caseinase & Oxidase & Catalase & Glucose \\
\hline R69 & + & - & + & - & - & + & + & - \\
\hline P78 & - & + & + & - & - & + & + & - \\
\hline M80 & - & + & - & - & - & + & + & - \\
\hline M96 & - & - & - & - & - & + & - & - \\
\hline T109 & + & - & + & - & - & + & + & - \\
\hline M127 & - & + & - & - & - & + & + & - \\
\hline M132 & - & + & + & - & - & + & + & - \\
\hline M135 & + & - & + & - & - & + & + & - \\
\hline M137 & - & - & - & - & - & + & - & - \\
\hline M139 & - & + & - & - & - & + & + & - \\
\hline M140 & - & - & - & - & - & + & - & - \\
\hline $\mathrm{PC} 1$ & - & + & + & - & - & + & + & - \\
\hline PC2 & - & - & + & - & - & + & + & - \\
\hline
\end{tabular}

$\mathrm{H}_{2} \mathrm{~S}$ : Hydrogen sulfide. 
that can co-exist in the same bacteria, although due to variable results, the commercial application of phosphatesolubilizing PGPR has been quite limited (Glick, 2012). Over all, out of 144 isolates, 63 were identified as phosphate solubilizers. Similar observations have been reported by Kumar et al. (2012) and Kayasth et al. (2013), although Rathaur et al. (2012) showed negative results.

The possible beneficial effect of pseudomonads on growth of tomato plant was evaluated. It was visually evident that the RL, germination percentage, and VI increased but to a varying extent, clarifies that the seed treatment generated a significant influence in RL, germination percentage and VI. Seedlings from seeds treated with the isolate JUP-M-140 showed highest RL of $20.96 \pm 1.55 \mathrm{~cm}$, germination of $100 \%$, and VI of 1363 This was followed by isolate JUP-R-68 (RL $20.24 \pm 0.98$ $\mathrm{cm}, 100 \%$ germination, and VI 1266). Seeds treated with JUP-M-138 showed an average RL of $20.23 \pm 1.53 \mathrm{~cm}$, $100 \%$ germination and VI of 1310 . Seeds treated with PC1 showed RL of $14.94 \pm 0.96 \mathrm{~cm}, 100 \%$ germination, and VI 1197.4, whereas seeds treated with and PC2 showed RL $17.2 \pm 0.94 \mathrm{~cm}, 100 \%$ germination, VI 1051.4) against distilled water control (RL $9.73 \pm 2.41 \mathrm{~cm}, 84 \%$ germination, VI of 529.2) shows that fluorescent isolates have positive impact on test plant. Impact of fluorescent pseudomonads on growth promotion and yield (Kumar et al., 2013) and their role as biocontrol agent has been reported (Salman et al., 2013). Use of PGPR to nurture soil fertility and improve growth and yield of agronomically important crops is a consequential alternative to chemical fertilizers in sustainable agriculture (Stajkovic et al., 2011).

In the present study, in vitro IAA production was validated by qualitative and quantitative methods. Qualitative analysis showed 63 isolates were positive for IAA production. Quantitative analysis showed maximum IAA production by the isolates JUP-M-137 (17 $\pm 0.96 \mu \mathrm{g}$ $\left.\mathrm{mL}^{-1}\right)$, JUP-C-2b1 $\left(15.4 \pm 2.15 \mu \mathrm{g} \mathrm{mL}^{-1}\right)$ and JUP-P-96 $\left(15.1 \pm 0.90 \mu \mathrm{g} \mathrm{mL}^{-1}\right)$. Control strains PC1 and PC2 showed a production of $9.1 \pm 0.89$ and $6.4 \pm 0.75 \mu \mathrm{g} \mathrm{mL}^{-1}$, respectively.

In the present study, the observed abundance of IAA did not result in significant root growth promotion in tomato seedlings, whereas isolates with moderate IAA production showed considerable root growth promotion. It can be considered that the analysis of in vitro activity of IAA production by bacteria does not necessarily reveal information about the ability to change in plant hormone levels (Schwachtje et al., 2012). Some isolates showed root augmentation even without IAA production, it seems likely due to significant biofilm formation and siderophore production. It was observed that all the fluorescent pseudomonad isolates forming biofilm, showed root growth promotion in tomato seedlings. With respect to the considered PGP traits, treated seeds showed enhanced germination with respect to controls seedlings. The well-established root growth promotion is one of the major criteria for the beneficial effects of PGPR. Rapid establishment of roots is advantageous for young seedlings as it increases their ability to anchor themselves to the soil and to obtain water and nutrients from their environment, therefore enhancing their chances for survival. Most root-promoting bacteria synthesize IAA and their effect on plants mimics that of exogenous IAA (Patten and Glick, 2002). It is known that auxins are quantitatively the most abundant phytohormones secreted by different PGPR and IAA affects plant cell division, extension and differentiation (Lee and Lee, 2010). They also play a major role in bacterial quorum sensing (de Bruijn et al., 2013). Nevertheless, the endogenous pool of plant IAA may be altered by the acquisition of IAA that has been secreted by soil bacteria. In this regard, the level of IAA synthesized by the plant is important in determining whether bacterial IAA stimulates or suppresses plant growth. Endogenous IAA may be suboptimal or optimal in plant roots and ancillary IAA that is taken up from bacteria could perhaps alter the IAA level to optimal or supra-optimal, resulting in plant growth promotion or inhibition (Glick, 2012).

Evaluations of 144 soil isolates from eight different soil samples showed 58 isolates were consistently positive for siderophore production on qualitative CAS assay. Studies on quantitative siderophore production was carried out in minimal salt medium, using in vitro CAS shuttle assay and maximum concentration of siderophore accumulation in the medium was by the isolate JUP-M-140 $(8.14 \pm 0.2 \mu \mathrm{M}$ $\left.\mathrm{L}^{-1}\right)$, JUP-M-137 $\left(8.02 \pm 0.03 \mu \mathrm{ML}^{-1}\right)$ and JUP-M-132 (5.98 $\left.\pm 0.1 \mu \mathrm{M} \mathrm{L}^{-1}\right)$. PC1 and PC2 showed $5.14 \pm 0.3$ and 3.18 $\pm 0.02 \mu \mathrm{M} \mathrm{L}^{-1}$ respectively under laboratory conditions. A peak shift was observed in the range of 400-420 nm on addition of ferric chloride stipulating the presence of hydroxamate nature of siderophores produced (Figure 3 ). It was further confirmed by the appearance of red color in presence of tetrazolium salt. Further studies confirmed the absence of catecholates and carboxylates, as no peaks were observed at 480 and 190-280 nm, respectively, which shows that the siderophores produced were hydroxamates.

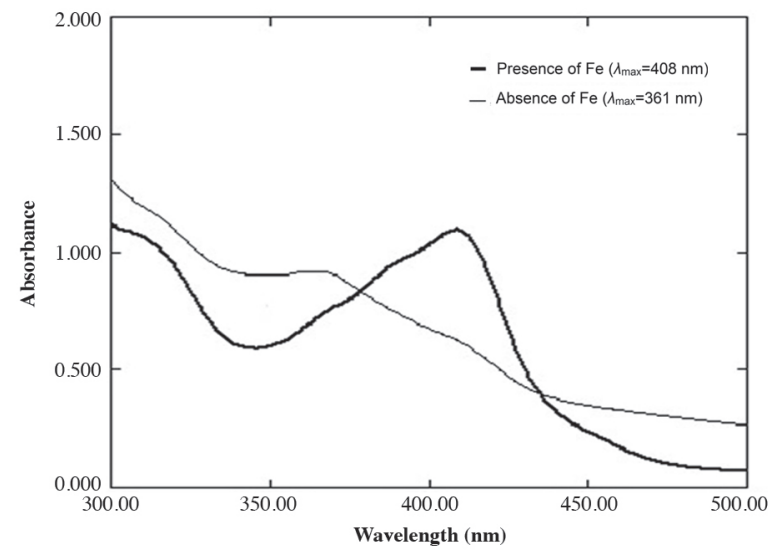

Figure 3. Absorbance of purified siderophore in presence and absence of ferric ammonium citrate $\left(\mathrm{Fe}^{3+}\right)$. 
Fluorescent siderophores are unique to fluorescent pseudomonads - an inherent trait that has implicated them as PGPR (Upadhyay and Srivastava, 2010) and many of the siderophore producing bacteria have been used as biocontrol agents to combat phytopathogens (Salman et al., 2013). An absorption peak between 365 and $410 \mathrm{~nm}$ indicates the presence of pyoverdin nature of siderophores, as per Bhattacharya (2010). Microbial siderophore may stimulate plant growth directly by increasing the iron availability in soil surrounding the roots or indirectly by competitively inhibiting the growth of plant pathogens with relatively less efficient iron uptake system. Production of hydroxamate siderophores is advantageous for its exploitation in agriculture as hydroxamate types are comparatively stable and has high iron chelating ability and nature of siderophore was found to be independent of habitat (Kloepper et al., 1980).

Significant biofilm formation was observed in the isolates JUP-T-16 $(11.49 \pm 0.16 \mathrm{~nm})$, JUP-T-78 (11.24 \pm $0.25 \mathrm{~nm})$ and JUP-P-84 $(11.22 \pm 1.28 \mathrm{~nm})$; quite similarly PC1 showed $8.1 \pm 0.80 \mathrm{~nm}$ and PC2 $7.64 \pm 1.3 \mathrm{~nm}$ depicts the ability of the isolate to survive in host rhizosphere through root colonization. PGP traits of PGPR are usually achieved by forming biofilms in the rhizosphere niche, which has advantages over planktonic mode of bacterial existence and biofilm assists them to increase the antibiotic resistance (Gauri et al., 2012). Biofilms are generally characterized by structural heterogeneity, genetic diversity, intricate community interactions and an extracellular matrix of polymeric substances. Some fluorescent pseudomonads produce phenazines, a group of small, redox-active compounds with diverse physiological functions which influence biofilm development across a large range of scales, but in unique ways for different Pseudomonas species (Ramos et al., 2010).

The antagonistic activity of pseudomonads against F. oxysporum (MTCC1755) was tested by in vitro well diffusion assay, which showed large variability in fungal antagonistic response. Plates were scanned after $7 \mathrm{~d}$ to monitor the zone of inhibition. In the tested 144 isolates, 42 showed different levels of antagonistic behavior. The highest detected zone for antifungal activity was shown by the isolate JUP-R-69 (59 $\pm 6.24 \mathrm{~mm}$ diameter) followed by JUP-P-80 (55 $\pm 5.29 \mathrm{~mm}$ diameter $)$ and JUP-T-19 (53 $\pm 8.54 \mathrm{~mm}$ diameter). Control strains PC1 and PC2 showed moderate action of inhibition with $34 \pm 4.36$ and $31 \pm 6.08 \mathrm{~mm}$ diameter, respectively. It is shown that the secondary metabolites such as benzoxazinoids from the roots can attract many soil bacteria playing a major role in chemotaxis (Neal et al., 2012). It has been reported that PGPR can produce multi-mechanism system of defense through production of various, lytic enzymes, volatile and diffusible defense compounds that must have played major role in the observed fungal inhibition (Gull and Hafeez, 2012; Selvakumar et al., 2013).

Over the nine parametric tests, i.e., PGP analysis and in vitro antagonistic experiments performed, the positive results gathered from the analysis were assigned from + to ++++ for the statistical analysis to generate ranking of pseudomonad isolate. Isolates in the present study were ranked by Kendall's concordance coefficient nonparametric analysis to shortlist the outperforming fluorescent pseudomonad isolates, where the highest ranking will be recorded as 1 . A collection of 144 newly isolated fluorescent pseudomonad strains from soil samples collected from 8 different sites eleven best isolates with ranking ranging from 1-10 have been shortlisted for further studies. PC1 and PC2 were ranked 9 and 3 respectively whereas JUP-M-140 was the best one with rank order 1 followed by JUP-M-139 and JUP-M-137 and 127 were significantly outperformed (Table 2). Two isolates were listed with a ranking 3 (M127 and M137) and three isolates each were listed with ranking 4 (P78, M96, and M132) and 10 (R69, M80, and T109). The

Table 2. Ranking of the bacterial isolates on application of the Kendall's concordance coefficient to the results of the tests designed to determine their plant growth promotion potential ${ }^{1}$.

\begin{tabular}{|c|c|c|c|c|c|c|c|c|c|c|c|c|c|}
\hline \multirow[b]{2}{*}{ PGP traits } & \multicolumn{11}{|c|}{ Pseudomonad strains (JUP) } & \multicolumn{2}{|c|}{ Control strains } \\
\hline & R69 & P78 & M80 & M96 & T109 & M127 & M132 & M135 & M137 & M139 & M140 & $\mathrm{PC} 1$ & PC2 \\
\hline Ammonia & + & + & + & + & + & + & + & + & + & + & + & + & + \\
\hline Hydrogen cyanide & + & + & + & + & + & + & + & + & + & + & - & + & ++ \\
\hline Phosphate & + & + & + & +++ & - & - & - & - & + & + & + & - & - \\
\hline Motility & ++ & + & + & + & + & +++ & + & + & ++ & + & ++ & + & + \\
\hline Root growth ${ }^{\mathrm{a}}$ & +++ & +++ & +++ & ++ & +++ & ++++ & +++ & ++++ & ++ & ++++ & ++++ & +++ & +++ \\
\hline Indole acetic acid ${ }^{\mathrm{b}}$ & ++ & ++ & ++ & ++++ & + & ++++ & +++ & ++ & ++++ & ++ & +++ & +++ & +++ \\
\hline Siderophore $^{c}$ & + & + & + & + & + & +++ & +++ & ++ & ++++ & +++ & ++++ & ++ & +++ \\
\hline Biofilm $^{\mathrm{d}}$ & + & ++++ & + & +++ & ++++ & +++ & +++ & ++ & +++ & ++++ & ++ & +++ & +++ \\
\hline Antagonism ${ }^{\mathrm{e}}$ & ++++ & +++ & ++++ & ++ & ++ & - & ++ & +++ & ++ & +++ & ++++ & +++ & +++ \\
\hline Score $\mathrm{f}^{\mathrm{f}}$ & 15 & 17 & 15 & 17 & 15 & 19 & 17 & 16 & 19 & 20 & 22 & 16 & 19 \\
\hline Ranking & 10 & 4 & 10 & 4 & 10 & 3 & 4 & 9 & 3 & 2 & 1 & 9 & 3 \\
\hline
\end{tabular}

PC1 and PC2 were Pseudomonas fluorescens NBAII and PFDWD, respectively.

1- No activity; + less activity; ++ moderate activity; +++ high activity; ++++: very high activity.

2- Ammonia, hydrogen cyanide, motility are analyzed qualitatively.

a $+<10,++10-14,+++14-18,++++>18(\mathrm{~cm})$

$\mathrm{b}_{+}<6,++6-9,+++9-12,++++>12\left(\mu \mathrm{g} \mathrm{mL}^{-1}\right)$.

c $+<3,++3-5,+++5-7,++++>7(\mu \mathrm{M})$.

$\mathrm{d}_{+}<3,++3-7,+++7-10,++++>10$ (optical density).

${ }^{\mathrm{e}}+<10,++10-30,+++30-50,++++>50(\mathrm{~mm})$.

${ }^{\mathrm{f}} \mathrm{Sum}$ of score. 
principal component analysis of the shortlisted isolates by the cross validation method showed that individual isolates were distributed far apart, differing widely in their nature (Figure 4). Axis 1 showed $38 \%$ and axis 2 showed $23 \%$ sample similarity indicates the diversity of fluorescent pseudomonad isolates.

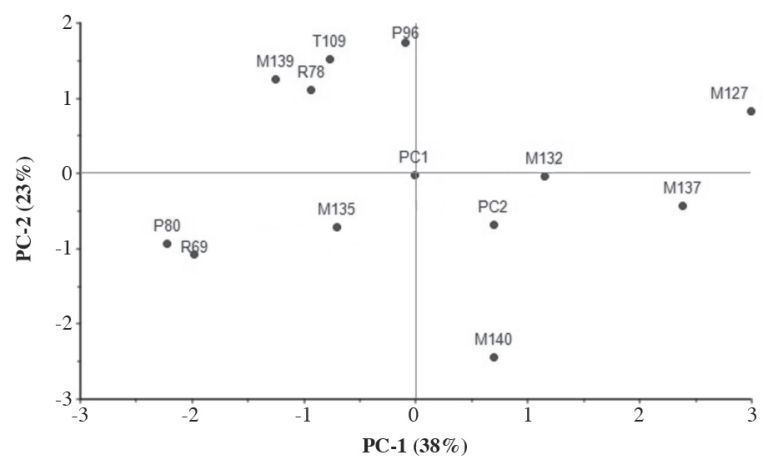

Figure 4. Principal component analysis (mean centered) of the shortlisted fluorescent pseudomonad isolates along with the control strains (PC1 and PC2). The percentage of variance is explained in the axis. Individual isolates are represented by symbols.

\section{CONCLUSION}

Previous studies have shown that plant growth promoting rhizobacteria exert specific growth promoting effects on plants, especially on hosts, presumably developed during long-term co-evolution. Nevertheless among the rhizobial pseudomonad isolates subjected to investigation, eighteen recovered from tomato rhizosphere, did not show significant growth promotion in tomato plants, except JUP-T-109 which ranked 10 in the final ranking. All others shortlisted isolates were from different plant rhizospheres, which did not show host dependent growth promotion. Although different studies have put forth various theories that affect root colonization, the major factors include the species, developmental stage and soil type which have been indicated as major elements determining the composition of rhizosphere-microbial communities. Rhizosphere of Nyctanthes arbor-tristis showed significant number of isolates which possess appreciable plant growth promotion traits. It is also worth to point out that the conventional hunting for rhizosphere bacteria were restricted to the agriculturally important, short living plant species, where as our results prove that other plants also harbors rich diversity in rhizosphere microorganisms, which needs more scientific attention. In this study, efficient isolation techniques along with various PGP variables and effectiveness of the isolates as biocontrol envoys have been considered. Our results indicate that the antagonistic activity and the role of these isolates in induction of resistance need to be explored Principal component analysis of biochemical characters and cluster analysis of molecular finger printing data showed the diversity among the fluorescent pseudomonad isolates.
The current study demonstrates the ability of fluorescent pseudomonad isolates to promote root length in tomato plants and antagonize $F$. oxysporum MTCC1755. It must be underlined that the ability of fluorescent pseudomonads to subvert fungal pathogens is a promising way to modulate the plant defense strategies, in terms of competitive survival in rhizobiome. Identification of new potential biocontrol strains is a contribution to agriculture in order to control the plant diseases, may help to reform the multidecade old mainstream pesticide based disease management approaches. Since most of the shortlisted fluorescent pseudomonad isolates shown a better plant growth promotion properties than the commercial test strains, which offers a better expertise in biocontrol strategies.

\section{ACKNOWLEDGEMENTS}

Authors are grateful to the Jain University for the financial and infrastructure support. We are extremely thankful to Prof. Leela Iyengar for her constructive comments and RomVijay Biotech, Puducherry, for the control strains of P. fluorescens. We acknowledge Dr. K.C. Suresh, biostatistician (PDADMAS) for his help in critical statistical analysis.

\section{LITERATURE CITED}

Alexander, M. 1965. Denitrifying bacteria. In Black, C.A. (eds.) Methods of soil analysis. Part 2. Chemical and microbiological properties. American Society of Agronomy, Madison, Wisconsin, USA.

Alexander, D.B., and D.A. Zuberer. 1991. Use of chrome azurol $\mathrm{S}$ reagents to evaluate siderophore production by rhizosphere bacteria. Biology and Fertility of Soils 12:39-45.

Ali, S.S., and N.N. Vidhale. 2011. Evaluation of siderophore produced by different clinical isolate Pseudomonas aeruginosa Indian Journal of Medical Research 3:131-135.

Baki, A.A., and J.D. Anderson. 1973. Vigor determination in soybean seed by multiple criteria. Crop Science 13:630-633.

Beneduzi, A., A. Ambrosini, and L.M.P. Passaglia. 2012. Plant growth-promoting rhizobacteria (PGPR): Their potential as antagonists and biocontrol agents. Genetics and Molecular Biology 35:1044-1051.

Bhattacharya, A. 2010. Siderophore mediated metal uptake by Pseudomonas fluorescens and its comparison to iron (iii) chelation. Ceylon Journal of Science 39:147-155.

Bhattacharyya, P.N., and D.K. Jha. 2012. Plant growth-promoting rhizobacteria (PGPR): Emergence in agriculture. World Journal of Microbiology and Biotechnology 28:1327-1350.

Bric, J.M., R.M. Bostock, and S.E. Silverstone. 1991. Rapid in situ assay for indoleacetic acid production by bacteria immobilized on a nitrocellulose membrane. Applied and Environmental Microbiology 57:535-538.

Cappuccino, J.C., and N. Sherman. 1992. In Microbiology: A laboratory manual. $3^{\text {rd }}$ ed. Benjamin/Cummings Science Publishing, New York, USA.

Choi, G.J., J.C. Kim, E.J. Park, Y.H. Choi, K.S. Jang, H.K. Lim, et al. 2006. Biological control activity of two isolates of Pseudomonas fluorescens against rice sheath blight. Journal of Plant Pathology 22:289-294.

de Bruijn, F.J., B. Drogue, E. Combes-Meynet, Y. MoënneLoccoz, F. Wisniewski-Dyé, and C. Prigent-Combaret. 2013. Control of the cooperation between plant growth-promoting rhizobacteria and crops by rhizosphere signals. Microbial Ecology doi:10.1002/9781118297674.ch27. 
de Weert, S., H. Vermeiren, I.H.M. Mulders, I. Kuiper, N. Hendrickx, G.V. Bloemberg, et al. 2002. Flagella-driven chemotaxis towards exudate components is an important trait for tomato root colonization by Pseudomonas fluorescens. Molecular PlantMicrobe Interactions 15:1173-1180.

Fallahzadeh-Mamaghani, V., M. Ahmadzadeh, and R. Sharifi. 2009. Screening systemic resistance-inducing fluorescent pseudomonads for control of bacterial blight of cotton caused by Xanthomonas campestris pv. malvacearum. Journal of Plant Pathology 91:663-670.

García-Gutiérrez, L., D. Romero, H. Zeriouh, F.M. Cazorla, J.A. Torés, A. de Vicente, et al. 2012. Isolation and selection of plant growth-promoting rhizobacteria as inducers of systemic resistance in melon. Plant and Soil doi:10.1007/s11104-012-1173-Z.

Gauri, S.S., S.M. Mandal, and B.R. Pati. 2012. Impact of Azotobacter exopolysaccharides on sustainable agriculture. Applied Microbiology and Biotechnology 95:331-338.

Glick, B.R. 2012. Plant growth-promoting bacteria: Mechanisms and applications. Scientifica doi:10.6064/2012/963401 .

Gull, M., and F.Y. Hafeez. 2012. Characterization of siderophore producing bacterial strain Pseudomonas fluorescens Mst 8.2 as plant growth promoting and biocontrol agent in wheat. African Journal of Microbiology Research 6:6308-6318.

Haas, D., and G. Défago. 2005. Biological control of soil-borne pathogens by fluorescent pseudomonads. Nature Reviews Microbiology doi:10.1038/nrmicro1129.

ISTA. 1993. International rules for seed testing. Seed Science and Technology 21:141-186.

Karuppiah, P., and S. Rajaram. 2011. Exploring the potential of chromium reducing Bacillus sp. and there plant growth promoting activities. Journal of Microbiology 1:17-23.

Kayasth, M., V. Kumar, and R. Gera. 2013. Exploring the potential of PGPR strain Bacillus licheniformis to be developed as multifunctional biofertilizer. Central European Journal of Biology 2:12-17.

Kloepper, J.W., J. Leong, M. Teintz, and M.N. Schroth. 1980. Pseudomonas siderophores: a mechanism explaining disease suppressive soil. Current Microbiology 4:317-320.

Kumar, A., A. Kumar, S. Devi, S. Patil, C. Payal, and S. Negi. 2012. Isolation, screening and characterization of bacteria from rhizospheric soils for different plant growth promotion (PGP) activities: an in vitro study. Recent Research in Science and Technology 4:1-5.

Kumar, S.S., R.K.M. Rao, R.D. Kumar, P. Sachin, and C.S. Prasad. 2013. Biocontrol by plant growth promoting rhizobacteria against black scurf and stem canker disease of potato caused by Rhizoctonia solani. Archives of Phytopathology and Plant Protection 46:487-502.

Lee, J.H., and J. Lee. 2010. Indole as an intercellular signal in microbial communities. FEMS Microbiology Reviews 34:426-444.

Lorck, H. 1948. Production of hydrocyanic acid by bacteria. Physiologia Plantarum 1:142-146.

Murinda, S.E., L.T. Nguyen, S.J. Ivey, R.A. Almeida, and S.P. Oliver. 2002. Novel single-tube agar-based test system for motility enhancement and immunocapture of Escherichia coli O157:H7 by $\mathrm{H} 7$ flagellar antigen-specific antibodies. Journal of Clinical Microbiology 40:4685-4690.

Neal, A.L., S. Ahmad, R. Gordon-Weeks, and J. Ton. 2012. Benzoxazinoids in root exudates of maize attracts Pseudomonas putida to the rhizosphere. PLOS One 7:1-14.

Neilands, J.B. 1981. Microbial iron compounds. Annual Review of Biochemistry 50:715-731.

Palleroni, N.J. 1984. Gram-negative, aerobic rods and cocci: family: 1. Pseudomonadaceae. In Krieg, N.R., and J.G. Holt (eds.) Bergy's manual of systematic bacteriology. Williams and Wilkins, Baltimore, Maryland, USA.

Patten, C.L., and B.R. Glick. 2002. Role of Pseudomonas putida indole acetic acid in development of the host plant root system. Applied Environmental Microbiology 68:3795-3801.
Pedraza, R.O., A. Ramirez-Mata, M.L. Xiqui, and B.E. Baca. 2004. Aromatic amino acid aminotransferase activity and indole-3acetic acid production by associative nitrogen-fixing bacteria. FEMS Microbiology Letters 233:15-21.

Ramos, I., L.E.P. Dietrich, A. Price-Whelan, and D.K. Newman. 2010. Phenazines affect biofilm formation by Pseudomonas aeruginosa in similar ways at various scales. Research in Microbiology 161:187-191.

Rathaur, P., P.W. Ramteke, W. Raja, and S.A. John. 2012. Isolation and characterization of nickel and cadmium tolerant plant growth promoting rhizobacteria from rhizosphere of Withania somnifera. Journal of Environmental Sciences 6:253-261.

Raval, A.A., and P.B. Desai. 2012. Rhizobacteria from rhizosphere of sunflower (Helianthus annuus L.) and their effect on plant growth. Research Journal of Recent Sciences 1:58-61.

Saharan, B.S., and V. Nehra. 2011. Plant growth promoting rhizobacteria: A critical review. Life Science and Medicine Research 21:1-30.

Salman, M., R. Abuamsha, and S. Barghouthi. 2013. Interaction of fluorescent pseudomonads with Pythium ultimum and Rhizoctonia solani in Cucumber roots. American Journal of Agricultural Economics 3:240-251.

Schwachtje, J., S. Karojet, S. Kunz, S. Brouwer, and J.T. van Dongen. 2012. Plant-growth promoting effect of newly isolated rhizobacteria varies between two Arabidopsis ecotypes. Plant Signal and Behavior 7:623-627.

Schwyn, R., and J.B. Neilands. 1987. Universal chemical assay for detection and determination of siderophores. Analytical Biochemistry 160:47-56.

Selvakumar, G., P.K. Mishra, J.C. Bhatt, P. Joshi, G.K. Joshi, H.S. Gupta, et al. 2011. Pseudomonas lurida M2RH3 (MTCC 9245), a psychrotolerant bacterium from the Uttarakhand Himalayas, solubilizes phosphate and promotes wheat seedling growth. World Journal of Microbiology and Biotechnology 27:11291135 .

Selvakumar, G., R. Reetha, and P. Thamizhiniyan. 2013. The PGPR as elicitors of plant defence mechanisms and growth stimulants on tomato (Lycopersicum esculentum Mill.) Botany Research International 6: 47-55.

Sharma, S., V. Kumar, and R.B. Tripathi. 2011. Isolation of phosphate solubilizing microorganism (PSMs) from soil. Journal of Microbiology and Biotechnology Research 1:90-95.

Shenker, M., I. Oliver, M. Helmann, Y. Hadar, and Y. Chen. 1992. Utilization by tomatoes of iron mediated by a siderophore produced by Rhizopus arrhizus. Journal of Plant Nutrition 15:2173-2182.

Snow, G.A. 1954. Mycobactin, a growth factor for Mycobacterium johnei: II. Degradation and identification of fragments. Journal of Chemical Society 1954:2588-2596.

Stajkovic, O., D. Delic, D. Josic, D. Kuzmanović, N. Rasulic, and J. Knezevic-Vukcevic. 2011. Improvement of common bean growth by co-inoculation with rhizobium and plant growthpromoting bacteria. Romanian Biotechnological Letters 16:5919-5926.

Upadhyay, A., and S. Srivastava. 2010. Evaluation of multiple plant growth promoting traits of an isolate of Pseudomonas fluorescens strain Psd. Indian Journal of Experimental Biology 48:601-609.

Yamaga, F., K. Washio, and M. Morikawa. 2010. Sustainable biodegradation of phenol by Acinetobacter calcoaceticus P23 isolated from the rhizosphere of Duckweed Lemna aoukikusa. Environmental Science and Technology 44:6470-6474.

Zhuang, X., J. Gao, A. Ma, S. Fu, and G. Zhuang. 2013. Bioactive molecules in soil ecosystems: masters of the underground. International Journal of Molecular Sciences 14:8841-8868.

Zongzheng, Y., L. Xin, L. Zhong, P. Jinzhao, Q. Jin, and Y. Wenyan. 2009. Effect of Bacillus subtilis SY1 on antifungal activity and plant growth. International Journal of Agricultural and Biological Engineering 2:55-56 